\title{
miR-369I-5p promotes hepatocellular carcinoma cell migration and invasion through activating PI3K/Akt signaling by targeting PTEN
}

This article was published in the following Dove Press journal: OncoTargets and Therapy

\section{Wei Du ${ }^{1, *}$ \\ Xu Zhang ${ }^{1, *}$ \\ Zhen Wan ${ }^{2}$}

'Department of Clinical Medicine, School of Queen Mary, Nanchang University, Nanchang, 330006, People's Republic of China; ${ }^{2}$ Department of General Surgery, the First Affiliated Hospital of Nanchang University, Nanchang 33006, People's Republic of China

*These authors contributed equally to this work
Correspondence: Zhen Wan

Department of General Surgery, the First Affiliated Hospital of Nanchang

University, Nanchang 33006, People's

Republic of China

Email wanzhen0II@I26.com
Background: The enhanced ability of cancer metastasis is the major cause for the cancerrelated death of hepatocellular carcinoma (HCC). Better understanding the mechanisms for the motility of cancer cells will benefit the treatment. Accumulating evidence suggests that aberrant microRNA (miRNA) expression contributes to HCC development and progression, whereas miR-3691-5p has not been reported in HCC.

Purpose: The aim of this study was to elucidate the expression, function and mechanism of miR-3691-5p in HCC.

Methods: Real-time quantitative polymerase chain reaction (qPCR) was performed to detect miR-3691-5p expression in HCC tissues and cell lines database analysis were conducted for detection of the expression of miR-3691-5p in HCC. Then, the association of miR-3691-5p with clinicopathological features of HCC patients were statistically measured. Subsequently, we attempted to observe the effects of miR-3691-5p on migration and invasion of HCC cells by transwell assays. Furthermore, bioinformatics tools and luciferase reporter gene assay as well as recuse experiments were conducted to explore the target of miR-3691-5p in HCC, and to explore whether the target mediated the effects of miR-3691-5p HCC cells.

Results: In the current study, we found that miR-3691-5p expression was elevated in both HCC tissues and cell lines, which was significantly correlated with poor prognosis and clinicopathological features including TNM stage $(P=0.016)$ and vascular invasion $(P=0.016)$. Furthermore, gain-or loss-of function assays demonstrated that miR-3691-5p promoted HCC cell migration and invasion. Luciferase reporter assay confirmed that PTEN was a direct downstream target of miR-3691-5p. Recuse assays showed that restoration of PTEN reversed the effects of miR-3691-5p on HCC cell migration and invasion through decreasing PI3K/Akt signaling.

Conclusion: Our results demonstrated that miR-3691-5p contributes to HCC cell migration and invasion through activating PI3K/Akt signaling by targeting PTEN.

Keywords: miR-3691-5p, hepatocellular carcinoma, PTEN, PI3K/Akt, migration, invasion

\section{Introduction}

Hepatocellular carcinoma (HCC), one of the most common cancer, represents the third leading cause of cancer-related mortality worldwide. ${ }^{1-3}$ China alone accounts for about half of the total number of cases and deaths due to the prevalence of hepatitis B virus. ${ }^{4,5}$ In spite of advances in diagnostic and treatment strategies, the prognosis of patients with HCC remains poor because of the metastasis and recurrence. ${ }^{6,7}$ For these reasons, the identification of key molecules involved in 
HCC progression is urgent and highly demanded for improving the clinical outcome.

microRNAs (miRNAs) are small non-coding RNA molecules which regulate target genes by a posttranscriptional mechanism. Extensive studies indicate that miRNAs function as tumor promoting or suppressive factors to regulate tumor cell phenotypes including cell proliferation, $^{8}$ cell cycle, ${ }^{9}$ invasion, ${ }^{10,11}$ migration, ${ }^{12,13}$ autophagy, ${ }^{14}$ and cellular senescence. ${ }^{15}$ However, whether and how miR-3691-5p is involved in the progress of HCC metastasis, invasion and migration is unknown.

Phosphatase and tensin homolog (PTEN) as a tumour suppressor has been extensively studied in several tumor types including glioblastoma, ${ }^{16}$ breast cancer, ${ }^{17}$ endometrial cancer, ${ }^{18}$ ovarian cancer, ${ }^{19}$ lung cancer, ${ }^{20}$ prostate cancer, ${ }^{21}$ colorectal cancer ${ }^{22}$ and HCC. ${ }^{23}$ Previous studies have indicated a plethora of different miRNAs have been linked to PTEN regulation in human cancers including miR-19a in leukaemia, ${ }^{24}$ miR-22 in prostate $^{25}$ and miR-26a in highgrade glioma ${ }^{26}$ and miR-21 in HCC. ${ }^{27}$ However, the relationship between PTEN and miR-3691-5p in HCC remains unknown.

In the present study, we demonstrated a significant increase of miR-3691-5p in HCC tissues and cells, which was correlated with poor prognosis and clinic pathological features. Our studies showed that miR-3691-5p promoted HCC cell migration and invasion through activating PI3K/ Akt signaling by targeting PTEN. In conclusion, we demonstrated that miR-3691-5p functions as an oncogene in HCC.

\section{Methods and materials}

\section{Tissue samples}

Tissue samples were obtained from 43 patients who were undergoing liver resection in the Department of General Surgery at the First Affiliated Hospital of Nanchang University (Nanchang, China). The HCC patients did not receive any adjuvant therapy before surgery, such as chemotherapy or radiotherapy. All HCC and normal tissues were collected and restored in liquid nitrogen. All the patients were provided written informed consent. Approval was obtained from the Ethics Committee of Nanchang University. The clinicopathologic parameters of patients were shown in Table 1 .

\section{Cell culture, transfection and reagent}

HEK 293T, the human HCC cell lines (Hep3B, SMMC7721, MHCC97-L, MHCC97-H, HCCLM3) and the human
Table I Association between miR-369l-5p expression and clinicopathologic features of patients with hepatocellular carcinoma

\begin{tabular}{|c|c|c|c|c|}
\hline \multirow[t]{2}{*}{ Characteristics } & \multirow[t]{2}{*}{$\begin{array}{l}\text { Number } \\
(n=43)\end{array}$} & \multicolumn{2}{|c|}{$\begin{array}{l}\text { miR-369 I-5p } \\
\text { level }\end{array}$} & \multirow[t]{2}{*}{$P$-value } \\
\hline & & $\begin{array}{l}\text { High } \\
(n=22)\end{array}$ & $\begin{array}{l}\text { Low } \\
(n=2 I)\end{array}$ & \\
\hline $\begin{array}{l}\text { Age (years) } \\
\quad \geq 60 \\
\quad<60\end{array}$ & $\begin{array}{l}29 \\
14\end{array}$ & $\begin{array}{l}16 \\
6\end{array}$ & $\begin{array}{l}13 \\
8\end{array}$ & 0.449 \\
\hline $\begin{array}{l}\text { Gender } \\
\text { Male } \\
\text { Female }\end{array}$ & $\begin{array}{l}31 \\
12\end{array}$ & $\begin{array}{l}17 \\
5\end{array}$ & $\begin{array}{l}14 \\
7\end{array}$ & 0.438 \\
\hline $\begin{array}{l}\text { HBV infection } \\
\text { Negative } \\
\text { Positive }\end{array}$ & $\begin{array}{l}8 \\
35\end{array}$ & $\begin{array}{l}3 \\
19\end{array}$ & $\begin{array}{l}5 \\
16\end{array}$ & 0.390 \\
\hline $\begin{array}{l}\text { Liver cirrhosis } \\
\text { Absent } \\
\text { Present }\end{array}$ & $\begin{array}{l}4 \\
39\end{array}$ & $\begin{array}{l}1 \\
21\end{array}$ & $\begin{array}{l}3 \\
18\end{array}$ & 0.263 \\
\hline $\begin{array}{l}\text { AFP }(\mathrm{ng} / \mathrm{ml}) \\
\quad \leq 400 \\
\quad>400\end{array}$ & $\begin{array}{l}10 \\
33\end{array}$ & $\begin{array}{l}4 \\
18\end{array}$ & $\begin{array}{l}6 \\
15\end{array}$ & 0.656 \\
\hline $\begin{array}{l}\text { Tumor size } \\
\quad \leq 5 \mathrm{~cm} \\
>5 \mathrm{~cm}\end{array}$ & $\begin{array}{l}20 \\
23\end{array}$ & $\begin{array}{l}8 \\
14\end{array}$ & $\begin{array}{l}12 \\
9\end{array}$ & 0.172 \\
\hline $\begin{array}{l}\text { Tumor multiplicity } \\
\text { Single } \\
\text { Multiple }\end{array}$ & $\begin{array}{l}28 \\
15\end{array}$ & $\begin{array}{l}13 \\
9\end{array}$ & $\begin{array}{l}15 \\
6\end{array}$ & 0.396 \\
\hline $\begin{array}{l}\text { Vascular invasion } \\
\text { No } \\
\text { Yes }\end{array}$ & $\begin{array}{l}27 \\
16\end{array}$ & $\begin{array}{l}10 \\
12\end{array}$ & $\begin{array}{l}17 \\
4\end{array}$ & $0.016 *$ \\
\hline $\begin{array}{l}\text { Edmondson grade } \\
\qquad I+I I \\
\text { III+IV }\end{array}$ & $\begin{array}{l}24 \\
19\end{array}$ & $\begin{array}{l}10 \\
12\end{array}$ & $\begin{array}{l}14 \\
7\end{array}$ & 0.161 \\
\hline $\begin{array}{l}\text { TNM stage } \\
\qquad+I I \\
I I I+I V\end{array}$ & $\begin{array}{l}35 \\
8\end{array}$ & $\begin{array}{l}15 \\
7\end{array}$ & $\begin{array}{l}20 \\
1\end{array}$ & $0.016 *$ \\
\hline
\end{tabular}

Note: Statistically significant values are shown in bold $(* P<0.05)$.

immortalized normal hepatic cell line L02 were obtained from the Chinese Academy of Sciences (Shanghai, China). All cells were cultured in Dulbecco's Modified Eagle Medium (DMEM; Gibco, Grand Island, NY, USA) containing $10 \%$ fetal bovine serum (FBS; Gibco) with $1 \%$ penicillin-streptomycin (Sigma, St-Louis, MO, USA) in a humidified incubator containing of $5 \% \mathrm{CO}_{2}$ at $37{ }^{\circ} \mathrm{C}$.

The mimics control (miR-control, CmiR-SN0001-SN), miR-3691-5p mimics (miR-3691-5p, HmiR-SN1977-SN 
-12), inhibitors control (anti-miR-NC, CmiR-AN0001-SN) and miR-3691-5p inhibitors (anti-miR-3691-5p, HmiRAN1977-SN-20) were purchased from Genecopoeia (Guangzhou, China). PTEN expression plasmid (PTEN, SC119965), specific siRNA against PTEN (si-PTEN, SR321496) and their corresponding negative control (EV and si-control, PS100001 and SR30004) were constructed and purchased from OriGene (OriGene Technologies Inc., Rockville, MD, USA), and the sequences for PTEN siRNA and scrambled siRNA were shown in Table 2 . Cells transfection was performed with Lipofectamine 2000 reagent (Invitrogen, Carlsbad, CA, USA) according to the manufacturer's instructions. An Akt inhibitor, MK2206 (1 $\mu$ M; Selleck Chemicals, Houston, TX, USA) was used to treat $\mathrm{HCC}$ cells for $12 \mathrm{~h}$.

\section{Real-time quantitative polymerase chain reaction ( $\mathrm{PPCR})$}

Trizol (Invitrogen) was used to extract RNA from tissues and cells following as the manufacture procedure. TIANScript RT Kit (Tiangen Biotech, Beijing, China) was used to perform reverse transcription. Quantitative PCR were performed using TaqMan Human MiRNA Aaasy Kit (Genecopoeia) and SYBR Premix Ex Taq ${ }^{\mathrm{TM}}$ Kit (TaKaRa, Shiga, Japan). The primers for PTEN (HQP067630) and GAPDH (HQP006940) were purchased from Genecopoeia. The primers for miR-3691-5p (HmiRQP1977) and U6 (HmiRQP9001) were obtained from Genecopoeia. The sequences of primers have been shown in Table 3. Expression levels were quantified using the $2^{-\Delta \Delta \mathrm{Ct}}$ method. Each experiment was performed in triplicate.

\section{Cell migration and invasion assays}

Transwell chambers (Millipore, Burlington, MA, USA) were used for cell migration and invasion assays. For migration assays, $\mathrm{HCC}$ cells $\left(2 \times 10^{4}\right)$ in the upper chamber were cultured with serum-free DMEM, and the lower chamber was filled with $10 \%$ serum-containing DMEM. For invasion assays, HCC cells $\left(2 \times 10^{4}\right)$ were seeded on Matrigel-coated membrane

Table 2 Primers used in this study

\begin{tabular}{|l|l|}
\hline Name & Sequence \\
\hline $\begin{array}{l}\text { PTEN siRNA } \\
\text { sense }\end{array}$ & \\
antisense & 5'-GGCGCUAUGUGUAUUAUUAdTdT-3' \\
scrambled siRNA & 3'-dTdTCCGCGAUACACAUAAUAAU-5' \\
sense & 5'-UUCUCCGAACGUGUCACGUTT-3' \\
antisense & 5'-ACGUGACACGUUCGGAGAATT-3 \\
\hline
\end{tabular}

Table 3 Primers used in this study

\begin{tabular}{|l|l|}
\hline Name & Sequence \\
\hline PTEN forward & 5'-GGGTCTGAGTCGCCTGTCA-3 \\
PTEN reverse & 5'-GGGTCTGAGTCGCCTGTCA-3' \\
GAPDH forward & 5'-GAAGGTCGGAGTCAACGGATTT-3' \\
GAPDH reverse & 5'-ATGGGTGGAATCATATTGGAAC-3' \\
U6 forward & 5'-CTCGCTTCGGCAGCACA-3' \\
U6 reverse & 5'-AACGCTTCACGAATTTGCGT-3 \\
\hline
\end{tabular}

inserts. Then, the chamber was put into the cell culture plate and incubated at $37^{\circ} \mathrm{C}$ for $24 \mathrm{hrs}$. Subsequently, cells that migrated or invaded across the transwell membrane were fixed with $4 \%$ paraformaldehyde for $10 \mathrm{~min}$ and next stained with $0.1 \%$ crystal violet for $20 \mathrm{~min}$. Finally, the migratory and invasive cells were examined and counted under microscope.

\section{Western blotting}

Proteins from HCC cells and tissues were extracted with RIPA buffer, the concentration was measured with the BCA Kit. Then proteins were electrophoresed by $10 \%$ SDS-PAGE and transferred to PVDF membranes (BioRad, Hercules, CA, USA). Next, the membranes were blocked in 5\% non-fat milk and incubated with specific primary antibodies at $4{ }^{\circ} \mathrm{C}$ overnight. PTEN (1:1000, \#9188; Cell Signaling Technology, Danvers, MA, USA), Akt (1:1000, \#4691; Cell Signaling Technology), p-Akt (1:2000, \#4060; Cell Signaling Technology), GAPDH (1:1000, \#5174; Cell Signaling Technology) antibodies were used. After that, the membranes were incubated with the second antibody (anti-rabbit \#7074; Cell Signaling Technology) for $1 \mathrm{~h}$ at room temperature. Finally, the ECL reagent (Beyotime Institute of Biotechnology, Haimen, China) was applied for detection.

\section{Luciferase reporter assay}

The wild-type (WT) or mutant (MT) 3'UTR of PTEN mRNA were synthesized and inserted into downstream of the pEZXMT06 vector (Genecopoeia). HEK 293T cells transfected with miR-3691-5p mimics or inhibitors or the corresponding controls were transfected with PTEN -3'UTR-wt and PTEN -3 'UTR-mut, respectively. Cells were collected $48 \mathrm{~h}$ later and the luciferase activity was quantified using the Luc-Pair ${ }^{\mathrm{TM}}$ Duo- Luciferase Assay Kit (Genecopoeia).

\section{Statistical analysis}

Data are presented as the mean \pm standard and analyzed using GraphPad Prism 7.0 software. All experiments were repeated for at least 3 times. Student's $t$-test (two groups) 
and one-way ANOVA (multiple groups) were conducted to analyze the difference. Spearman's correlation analysis was performed to determine the correlation between miR-3691-5p and PTEN mRNA expression. ${ }^{*} P<0.05$, $* * P<0.01$ and $* * * P<0.001$ were taken as indicative of statistically significant difference.

\section{Results}

\section{Expression and clinical significance of miR-369l-5p in HCC}

Real-time quantitative PCR (qPCR) was performed to detect miR-3691-5p expression in 43 pairs HCC tissues and the adjacent non-tumor tissues. The results showed a higher expression of miR-3691-5p in HCC tissues than in non-tumor tissues $(P<0.001$, Figure 1A). In accordance, higher miR-3691-5p level was observed in HCC cell lines
(Hep3B, SMMC-7721, MHCC97-L, MHCC97-H, HCCLM3) compared to the immortalized normal liver cell line (L02) (Figure 1C). TCGA data from starBase v3.0 (http://starbase.sysu.edu.cn) showed that the level of miR-3691-5p was significantly lower in normal tissues than in HCC tissues $(P=0.018$, Figure $1 \mathrm{~B})$, and survival analysis showed that patients with high miR-3691-5p expression was correlated with worse overall survival (OS) $(P=0.016$, Figure 1D). To investigate the correlation between miR-3691-5p level and the clinicopathological features of HCC, patients were divided into miR-3691-5p high or low-group based on median value. Results showed that the high levels of miR-3691-5p were significantly associated with vascular invasion $(P=0.016)$ and advanced tumor-node-metastasis (TNM) stage $(P=0.016)$ (Table 1$)$. Collectively, miR-3691-5p is increased in HCC and could be used to predict the outcome of HCC patients.
A

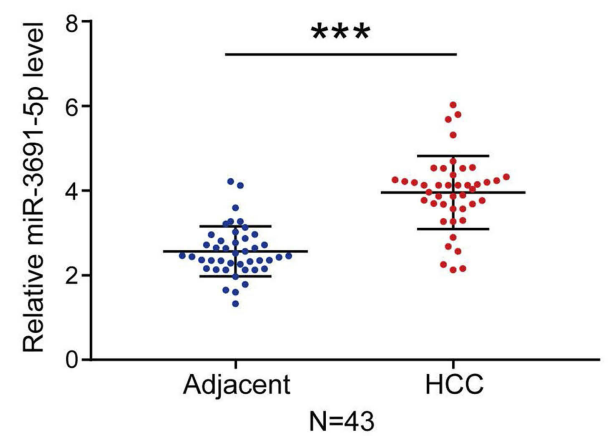

C

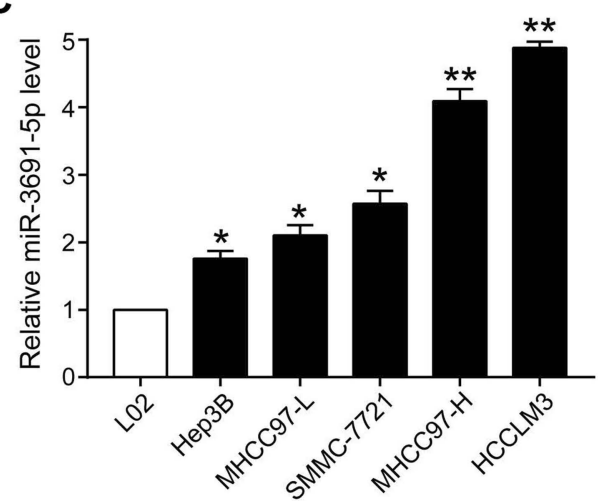

B

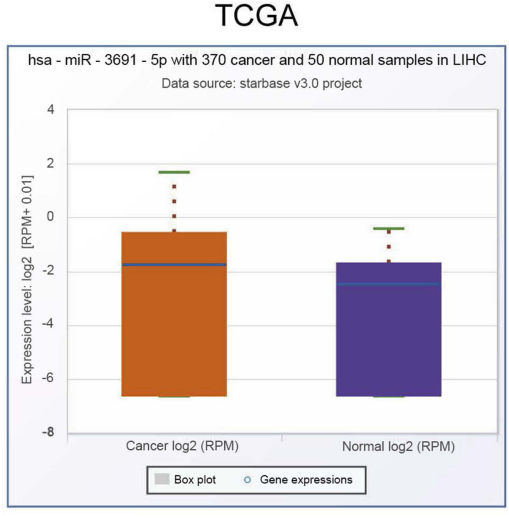

D

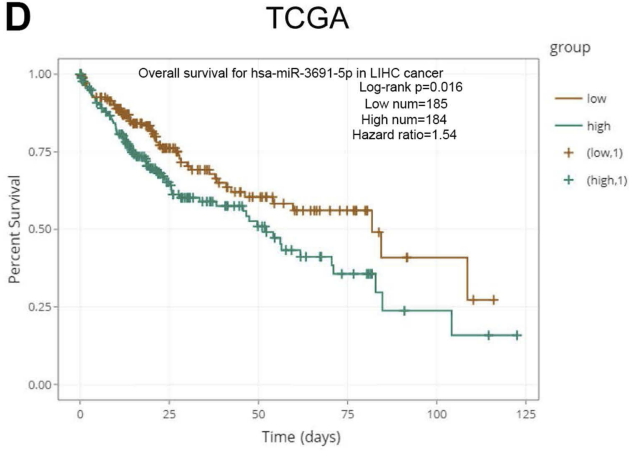

Figure I The expression and prognostic value of miR-369l-5p in HCC.

Notes: (A) The levels of miR-369l-5p in HCC and adjacent normal tissues ( $n=43$ ); (B) TCGA data from starbase v3.0 (http://starbase.sysu.edu.cn) showed that the levels of miR-369I-5p in normal tissues is higher than in HCC tissues $(P=0.018)$; (C) The levels of miR-369I-5p in HCC cell lines and L02 cells; (D) Data from TCGA showed that HCC patients with higher expression of miR-369l-5p had poorer overall survival $(P=0.016)$. Each experiment was performed three times. All data were presented as mean $\pm S D$. Student's $t$-test was conducted to analyze the difference. $* P<0.05, * * P<0.01, * * * P<0.001$.

Abbreviations: HCC, hepatocellular carcinoma, TCGA, The Cancer Genome Atlas; LIHC, liver hepatocellular carcinoma. 


\section{miR-369I-5p promotes HCC cell migration and invasion}

To investigate the biological function of miR-3691-5p on the migration and invasion of HCC cells in vitro, we constructed both miR-3691-5p overexpression and knockdown HCC cell lines using miR-3691-5p mimics in Hep3B and inhibitors in HCCLM3 cells, respectively. Transfection efficiency in Hep3B or HCCLM3 cells was confirmed by qPCR (Figure 2A). Results of transwell assay with or without matrigel showed that miR-3691-5p overexpression notably enhanced Hep3B cell migration and invasion, while knockdown of miR-3691-5p significantly inhibited HCCLM3 cell migration and invasion compared with controls (Figure $2 \mathrm{~B}$ and $\mathrm{C}$ ). These data suggested that miR-3691-5p promotes HCC cell migration and invasion.

\section{PTEN is a direct downstream of miR-369l-5p in HCC}

TargetScan (http://www.targetscan.org) were used to predict the targets of miR-3691-5p. PTEN was selected for further experimental validation, because the complementary sequence of miR-3691-5p was identified in the 3'UTR of PTEN mRNA (Figure 3A). The result of qPCR showed a lower level of PTEN mRNA in HCC tissues than in adjacent normal tissues (Figure 3B). A statistically significant inverse correlation was revealed by Spearman's correlation analysis between mRNA levels of miR-3691-5p and PTEN ( $\mathrm{r}=-0.7426, P<0.001$ ) (Figure 3C). Subsequently, qPCR and Western blotting were performed to test the level of PTEN in transfected Hep3B and HCCLM3 cells. The results revealed that miR-3691-5p overexpression decreased mRNA and protein expression of PTEN in Hep3B cells $(P<0.05)$ (Figure 3D and E). In contrast, knockdown of miR-3691-5p dramatically increased the mRNA and protein levels of PTEN in HCCLM3 $(P<0.05)$ (Figure $3 \mathrm{D}$ and F). The results of luciferase reporter gene assay showed that miR-3691-5p significantly suppressed luciferase activity of PTEN containing a wild-type 3'UTR but did not suppress activity of PTEN with a mutant 3'UTR $(P<0.05)$ (Figure 3G). Downregulation of miR-3691-5p by anti-miR-3691-5p increased the luciferase activity of PTEN $(P<0.05)$ (Figure 3G). The findings suggested PTEN is a direct target of miR-3691-5p in HCC.

\section{PTEN mediates the role of miR-369l-5p in HCC cells}

Rescue assays were conducted to illuminate whether PTEN participates in the facilitation of miR-3691-5p on

\section{A}
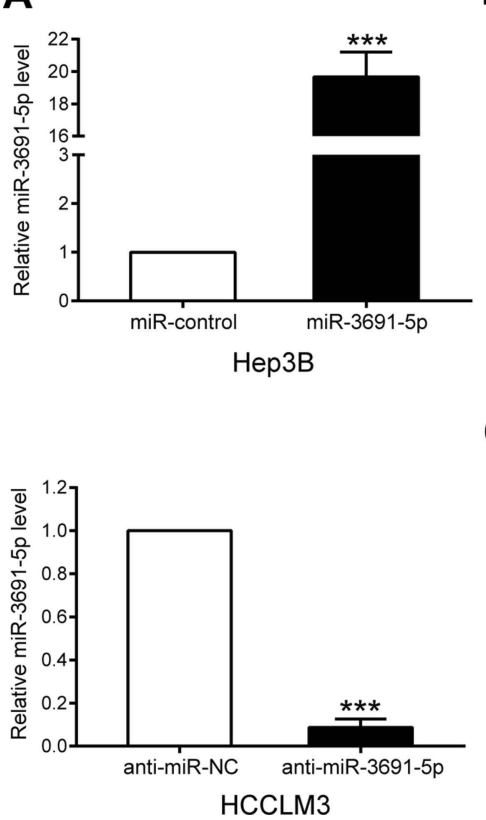

\section{B}
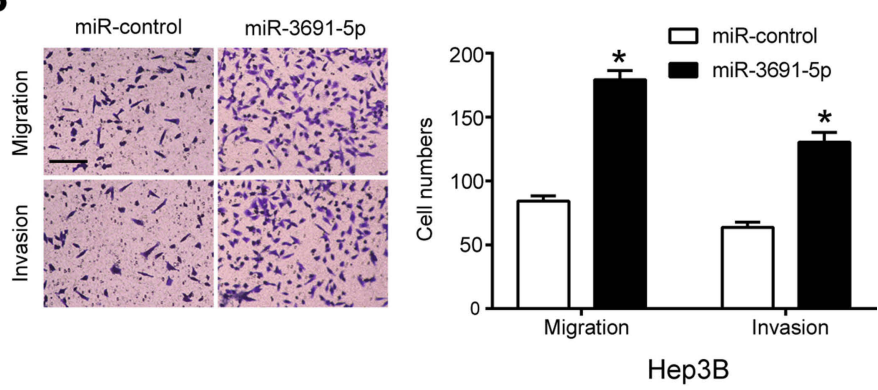

C

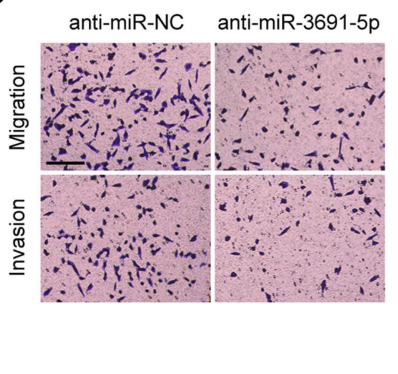

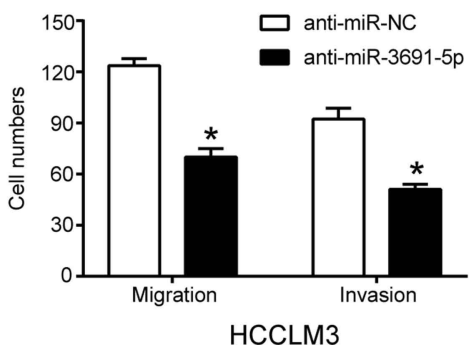

Figure 2 miR-369l-5p is a promotor of HCC cell migration and invasion in vitro.

Notes: (A) The transfection efficiencies of miR-369I-5p mimics and inhibitors in Hep3B or HCCLM3 cell were detected by qPCR. (B and C) Transwell assay of miR-369I$5 p$-overexpression Hep3B (B) or miR-369I-5p-silencing HCCLM3 (C); scale bars, $100 \mu \mathrm{m}$; magnification, 100x. Each experiment was performed three times. All data were presented as mean $\pm \mathrm{SD}$. Student's $t$-test was conducted to analyze the difference. $* P<0.05, * * * P<0.00 \mathrm{I}$. 
A

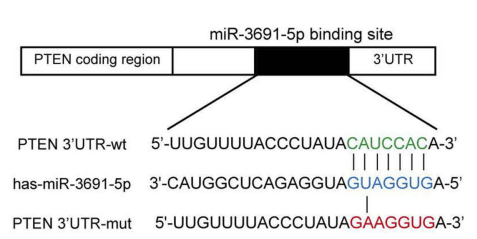

D
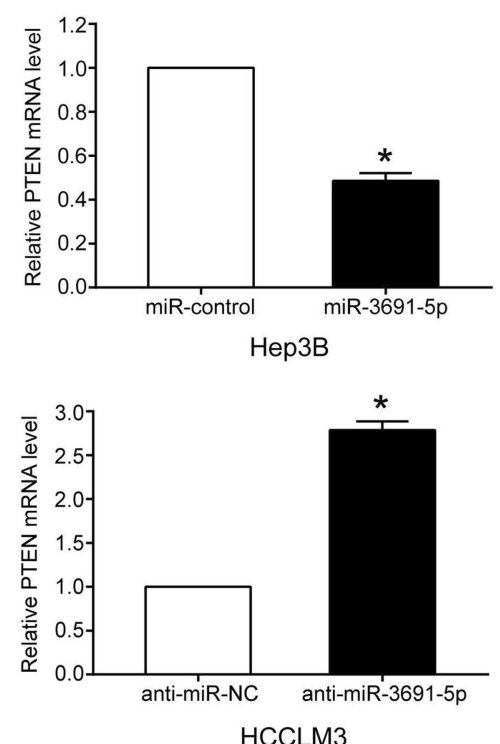

B

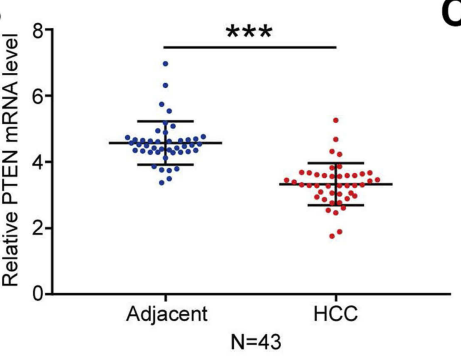

$\mathbf{E}$

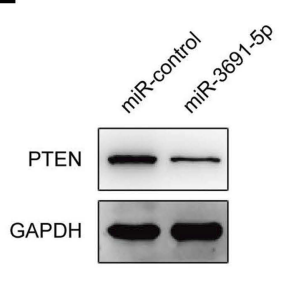

$\mathbf{F}$
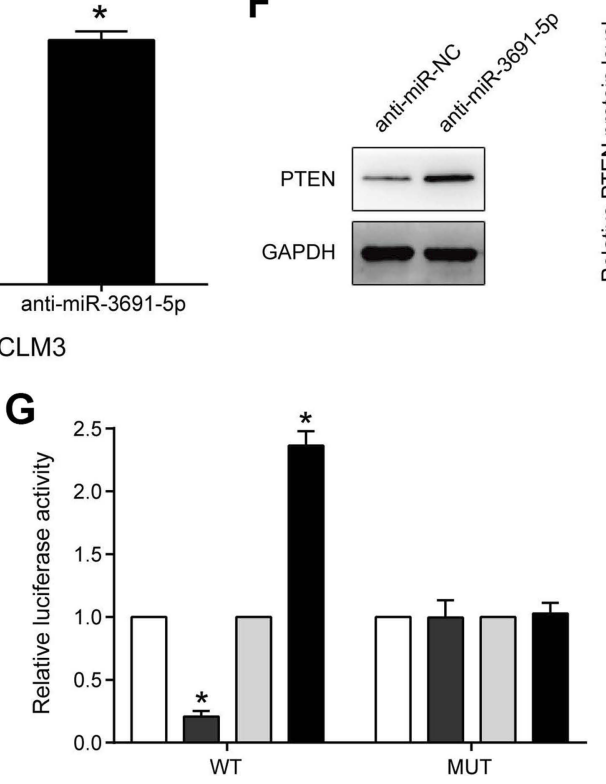

C
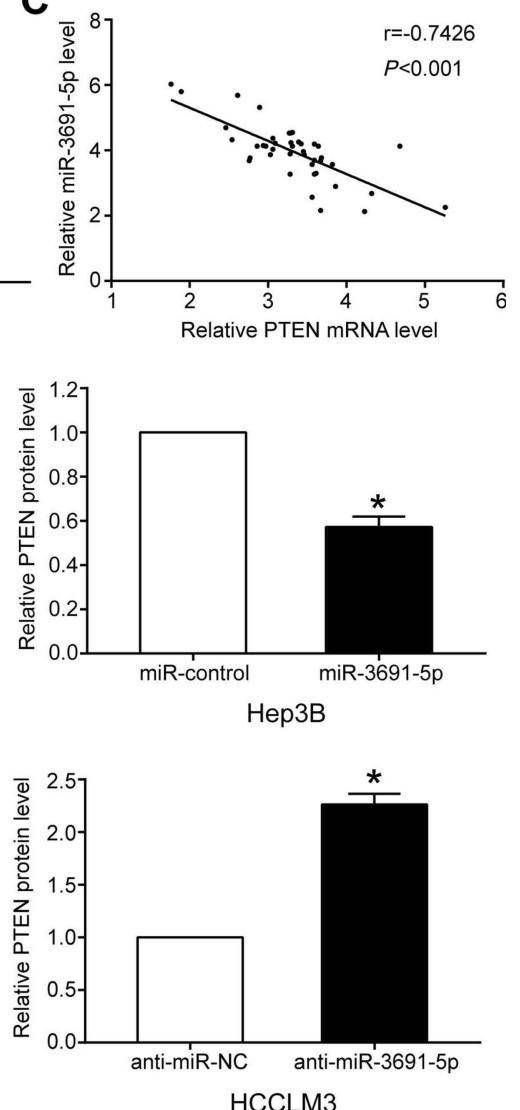

HCCLM3

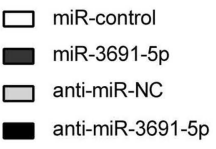

Figure 3 PTEN is a direct target of miR-369l-5p in HCC.

Notes: (A) miR-369I-5p and its putative binding sequence in the 3'UTR of PTEN. The mutant miR-369I-5p binding site was generated in the complementary site for the seed region of miR-369I-5p. (B) The mRNA levels of PTEN in 43 paired HCC and adjacent normal tissues. (C) Spearman's correlation analysis demonstrated that miR-369I$5 p$ expression level was inversely correlated with PTEN mRNA level in HCC tissues. (D) The mRNA levels of PTEN in overexpression or silencing miR-369I-5p in Hep3B or HCCLM3 cells, respectively. (E and $\mathbf{F}$ ) The protein levels of PTEN in overexpression or silencing miR-369I-5p in Hep3B or HCCLM3 cells, respectively. (G) miR-369I-5p significantly suppressed the luciferase activity that carried wt but not mt 3'UTR of PTEN. Anti-miR-369I-5p led to a dramatical increase in luciferase activity of wt 3'UTR of PTEN. Each experiment was performed three times. All data were presented as mean $\pm S D$. Student's $t$-test was conducted to analyze the difference. $* P<0.05$, $* * * P<0.00 I$. Abbreviations: HCC, hepatocellular carcinoma; wt, wild type; mut, mutant type.

migration and invasion in HCC cells. We increased PTEN expression in miR-3691-5p-overexpressing Hep3B cells (Figure 4A), and results of transwell assays revealed that the abilities of migration and invasion were weakened after PTEN upregulation $(P<0.05$, Figure 4B). Accordingly, PTEN silence with siRNAs enhanced the abilities of migration and invasion of HCCLM3-anti-miR $-3691-5 p$ cells $(P<0.05$, Figure $4 \mathrm{~A}$ and $\mathrm{C})$. These data showed that PTEN is a functional downstream mediator of miR-3691-5p in HCC.

\section{PI3K/Akt pathway is essential for the biological function of miR-369l-5p in $\mathrm{HCC}$}

Given that PTEN was a major negative regulator of PI3K/ Akt pathway, we further investigated whether miR-3691-5p 
A
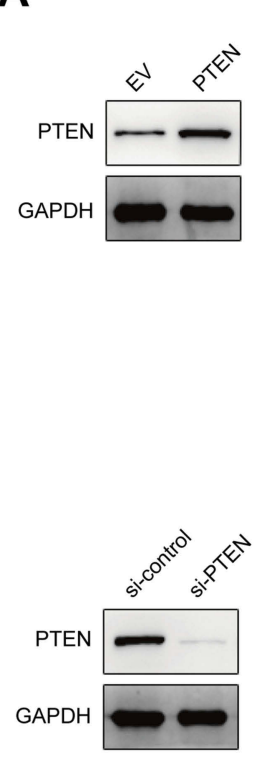
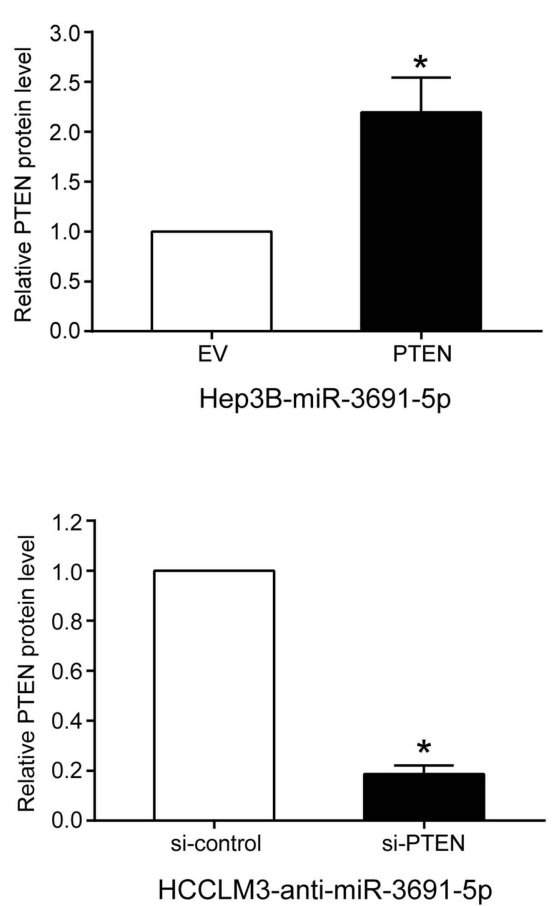

B

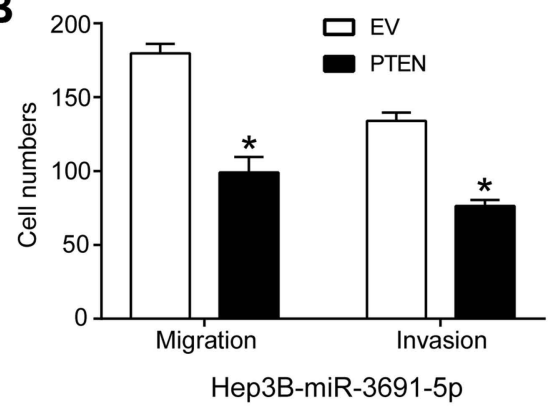

C

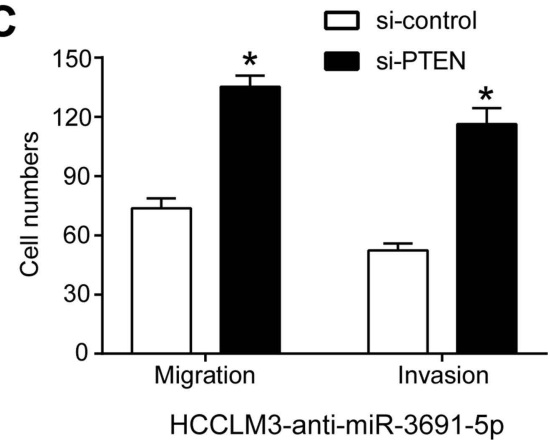

Figure 4 PTEN mediates the effects of miR-369I-5p on migration and invasion of HCC cells.

Notes: (A) PTEN expression level in miR-369I-5p-overexpressing Hep3B cells that were transfected with EV or PTEN expression plasmid or miR-369I-5p-silencing HCCLM3 cell that were transfected with control siRNA or PTEN siRNA. (B) The results of transwell assays revealed that the abilities of miR-369I-5p-overexpressing Hep3B cells migration and invasion were weakened after PTEN upregulation. (C) The results of transwell assays revealed that PTEN silence with siRNAs enhanced the abilities of migration and invasion of HCCLM3-antimiR-369I-5p cells. Each experiment was performed three times. All data were presented as mean $\pm S D$. Student's $t$-test was conducted to analyze the difference. $* P<0.05$.

Abbreviation: HCC, hepatocellular carcinoma.

could altered the activity of PI3K/Akt pathway in HCC cells. Results of Western blotting revealed that miR-3691-5p mimics increased the expression of p-Akt in Hep3B cell and miR-3691-5p inhibitors decreased the expression of p-Akt in HCCLM3 $(P<0.05$, Figure $5 \mathrm{~A}$ and B). To investigate whether PI3K/Akt pathway mediates the effects of miR3691-5p on migration and invasion of HCC cells, MK2206 (an Akt inhibitor) was used to block Akt activation in Hep3B cells with miR-3691-5p overexpression ( $P<0.05$, Figure 5C). Functional experiments revealed that inactivation of Akt inhibited miR-3691-5p-overexpressing Hep3B cells migration and invasion $(P<0.05$, Figure $5 \mathrm{D})$. These results demonstrated that $\mathrm{PI} 3 \mathrm{~K} /$ Akt signaling exerts an essential function during miR-3691-5p-induced HCC cell migration and invasion (Figure 6).

\section{Discussion}

In the recent years, increasing evidence has demonstrated that miRNAs, as non-coding RNAs, plays a vital role in the regulation of HCC progression. ${ }^{28-30}$ For example, dysregulation of miRNAs promotes the growth ${ }^{31,32}$ and metastasis $^{33,34}$ of HCC cells. Hence, identification of HCC specific miRNAs and their targets are critical for understanding their role in HCC progression and may be important for defining novel therapeutic targets. To our knowledge, the study is the first time to investigate the relationship between miR-3691-5p and HCC. In this study, we revealed that miR-3691-5p was upregulated in HCC tissues and cell lines, which was significantly correlated with poor prognosis and clinic pathological features including TNM stage and vascular invasion. Our results demonstrated that miR-3691-5p promoted HCC cell migration and invasion by gain and loss of function experiments. In conclusion, we demonstrated that miR3691-5p functions as an oncogene in HCC.

Ample evidence has shown that a variety of different miRNAs have been linked to PTEN regulation in human cancers including miR-19a in leukaemia, ${ }^{24}$ miR-22 in prostate $^{25}$ and miR-26a in high-grade glioma ${ }^{26}$ and miR21 in $\mathrm{HCC}^{27}$ However, the relationship between PTEN and miR-3691-5p has not been investigated in HCC. Here, we provided sufficient evidence that PTEN is a direct function target of miR-3691-5p in HCC. First, the level of miR-3691-5p was inversely correlated with the expression of PTEN in HCC tissues. Second, miR-3691-5p negatively modulated PTEN expression in HCC cells at the 
A
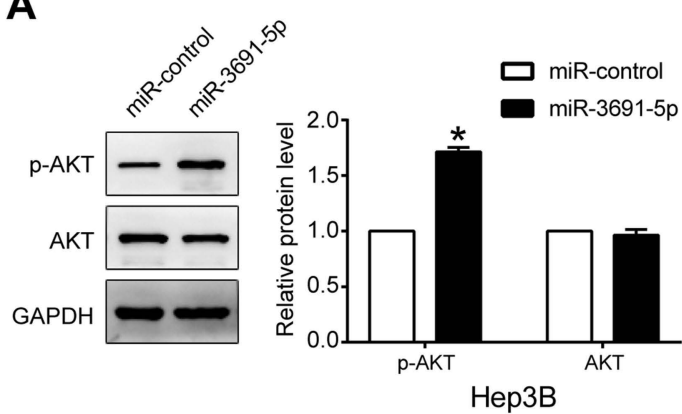

C
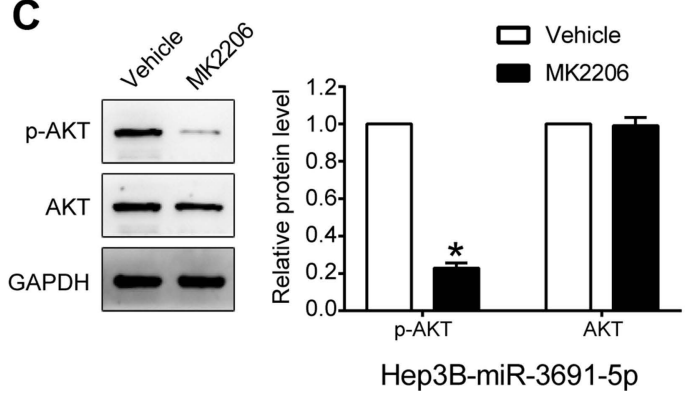

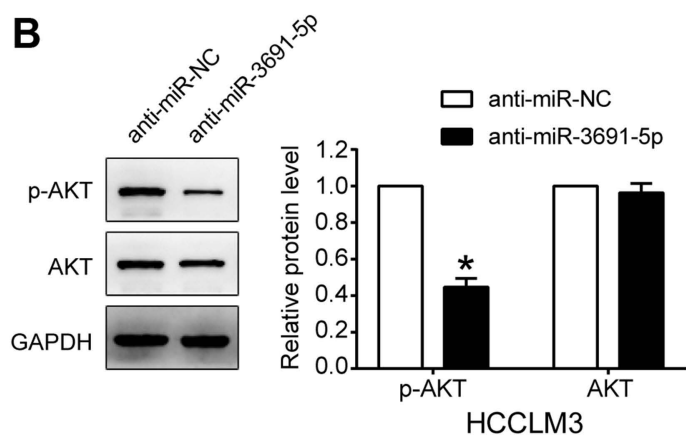

D

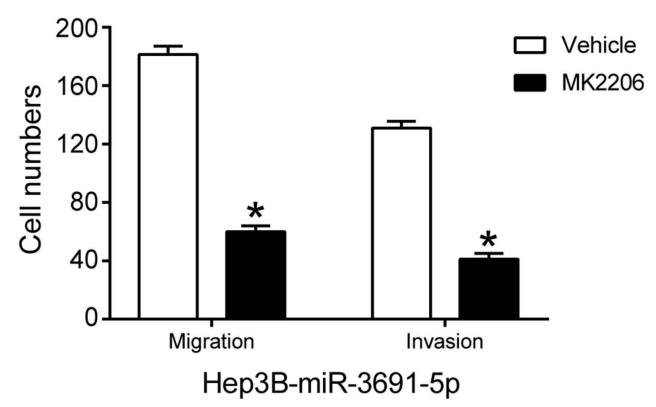

Figure 5 PI3K/Akt pathway is essential for the biological function of miR-369l-5p in HCC.

Notes: (A and B) Western blot analysis indicated that miR-369I-5p mimics increased the level of p-Akt in Hep3B cells. And miR-369I-5p inhibitors decreased the level of p-Akt in HCCLM3 cells. (C). The levels of p-Akt, Akt in miR-369l-5p-overexpressing Hep3B cells treated with MK2206 (an Akt inhibitor) and DMSO. (D) The results of transwell assay revealed that inactivation of Akt inhibited miR-369l-5p-overexpressing Hep3B cells migration and invasion. Each experiment was performed three times. All data were presented as mean \pm SD. Student's $t$-test was conducted to analyze the difference. $* P<0.05$.

Abbreviations: HCC, hepatocellular carcinoma; DMSO, dimethyl sulfoxide.

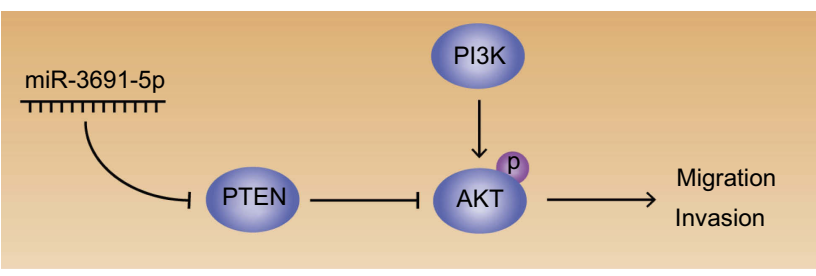

Figure 6 Abridged general view for the interplay among miR-369l-5p/PTEN/Akt pathway.

Note: In the regulatory network, miR-369l-5p activates Akt by targeting PTEN, thus promoting $\mathrm{HCC}$ cell migration and invasion ( $\rightarrow$ activation; $-\downarrow$ inhibition).

Abbreviation: HCC, hepatocellular carcinoma.

mRNA and protein levels. Third, miR-3691-5p affected the luciferase activity of wt-3'UTR but not of the mut3'UTR of PTEN. Finally, recuse assays showed that restoration of PTEN reverses the effects of miR-3691-5p on HCC cell migration and invasion through decreasing PI3K/Akt signaling. These results suggested that PTEN is a direct function target of miR-3691-5p, and mediates the role of miR-3691-5p in HCC cells.

In this study, we found that miR-3691-5p was significantly elevated in HCC tissues and cell lines, and correlated with poor prognosis and clinic pathological features, which promotes HCC cell migration and invasion through activating PI3K/Akt signaling by targeting PTEN. In conclusion, our results demonstrated that miR-3691-5p functions as an oncogene in $\mathrm{HCC}$

\section{Acknowledgments}

This work was supported by the grants from National Nature Science Foundation of China (No. 81760137), Jiangxi Province Science Foundation for Youths (No. 20161BAB215225) and Science and Technology Project Founded by the Education Department of Jiangxi Province (No. 150131).

\section{Disclosure}

The authors report no conflicts of interest in this work.

\section{References}

1. Bray F, Ferlay J, Soerjomataram I, Siegel RL, Torre LA, Jemal A. Global cancer statistics 2018: GLOBOCAN estimates of incidence and mortality worldwide for 36 cancers in 185 countries. CA Cancer J Clin. 2018;68:394-424. doi:10.3322/caac.21492

2. Miller KD, Siegel RL, Lin CC, et al. Cancer treatment and survivorship statistics, 2016. CA Cancer J Clin. 2016;66:271-289. doi:10.3322/caac.21349 
3. Siegel RL, Miller KD, Jemal A. Cancer statistics, 2018. CA Cancer J Clin. 2018;68:7-30. doi:10.3322/caac.21442

4. Islami F, Chen W, Yu XQ, et al. Cancer deaths and cases attributable to lifestyle factors and infections in China, 2013. Ann Oncol. 2017;28:2567-2574. doi:10.1093/annonc/mdx342

5. Chen W, Zheng R, Baade PD, et al. Cancer statistics in China, 2015. CA Cancer J Clin. 2016;66:115-132. doi:10.3322/caac.21338

6. Forner A, Reig M, Bruix J. Hepatocellular carcinoma. Lancet. 2018;391:1301-1314. doi:10.1016/S0140-6736(18)30010-2

7. Greten TF, Wang XW, Korangy F. Current concepts of immune based treatments for patients with HCC: from basic science to novel treatment approaches. Gut. 2015;64:842-848. doi:10.1136/gutjnl-2014-307990

8. Dou C, Zhou Z, Xu Q, et al. Hypoxia-induced TUFT1 promotes the growth and metastasis of hepatocellular carcinoma by activating the $\mathrm{Ca}$ (2+)/PI3K/AKT pathway. Oncogene. 2019;38:1239-1255. doi:10.1038/s41388-018-0505-8

9. Ma YS, Lv Z-W, Yu F, et al. MicroRNA-302a/d inhibits the self-renewal capability and cell cycle entry of liver cancer stem cells by targeting the E2F7/AKT axis. J Exp Clin Cancer Res. 2018;37:252. doi:10.1186/s13046-018-0927-8

10. Luo C, Yin D, Zhan H, et al. microRNA-501-3p suppresses metastasis and progression of hepatocellular carcinoma through targeting LIN7A. Cell Death Dis. 2018;9:535. doi:10.1038/s41419-018-0577-y

11. Liu Z, Wang Y, Dou C, et al. MicroRNA-1468 promotes tumor progression by activating PPAR-gamma-mediated AKT signaling in human hepatocellular carcinoma. J Exp Clin Cancer Res. 2018;37:49. doi:10.1186/s13046-018-0717-3

12. Roy S, Hooiveld GJ, Seehawer M, et al. microRNA 193a-5p regulates levels of nucleolar- and spindle-associated protein 1 to suppress hepatocarcinogenesis. Gastroenterology. 2018;155:1951-1966 e1926. doi:10.1053/j.gastro.2018.08.032

13. Tao J, Liu Z, Wang Y, et al. MicroRNA-645 represses hepatocellular carcinoma progression by inhibiting SOX30-mediated p 53 transcriptional activation. Int $J$ Biol Macromol. 2019;121:214-222. doi:10.1016/j.ijbiomac.2018.10.032

14. Wang J, Chen J, Liu Y, et al. Hepatitis B virus induces autophagy to promote its replication by the Axis of miR-192-3p-XIAP via NF-kappaB signaling. Hepatology. 2018. doi:10.1002/hep.30248

15. Shiu TY, Shih Y-L, Feng A-C, et al. HCV core inhibits hepatocellular carcinoma cell replicative senescence through downregulating microRNA-138 expression. $J$ Mol Med. 2017;95:629-639. doi:10.1007/s00109-017-1518-4

16. Benitez JA, Ma J, D'Antonio M, et al. PTEN regulates glioblastoma oncogenesis through chromatin-associated complexes of DAXX and histone H3.3. Nat Commun. 2017;8:15223. doi:10.1038/ncomms15223

17. Ngeow J, Sesock K, Eng C. Breast cancer risk and clinical implications for germline PTEN mutation carriers. Breast Cancer Res Treat 2017;165:1-8. doi:10.1007/s10549-015-3665-z

18. Bian X, Gao J, Luo F, et al. PTEN deficiency sensitizes endometrioid endometrial cancer to compound PARP-PI3K inhibition but not PARP inhibition as monotherapy. Oncogene. 2018;37:341-351. doi:10.1038/onc.2017.326

19. Wang Y, Zhao S, Zhu L, Zhang Q, Ren Y. MiR-19a negatively regulated the expression of PTEN and promoted the growth of ovarian cancer cells. Gene. 2018;670:166-173. doi:10.1016/j.gene.2018.05.063

20. Malaney P, Palumbo E, Semidey-Hurtado J, et al. PTEN physically interacts with and regulates E2F1-mediated transcription in lung cancer Cell Cycle. 2018;17:947-962. doi:10.1080/15384101.2017.1388970
21. Wise HM, Hermida MA, Leslie NR. Prostate cancer, PI3K, PTEN and prognosis. Clin Sci. 2017;131:197-210. doi:10.1042/CS20160026

22. Therkildsen C, Bergmann TK, Henrichsen-Schnack T, Ladelund S, Nilbert M. The predictive value of KRAS, NRAS, BRAF, PIK3CA and PTEN for anti-EGFR treatment in metastatic colorectal cancer: A systematic review and meta-analysis. Acta Oncol. 2014;53:852-864. doi:10.3109/0284186X.2014.895036

23. Wan XW, Jiang M, Cao H-F, et al. The alteration of PTEN tumor suppressor expression and its association with the histopathological features of human primary hepatocellular carcinoma. $J$ Cancer Res Clin Oncol. 2003;129:100-106. doi:10.1007/ s00432-002-0410-x

24. Li Y, Vecchiarelli-Federico LM, Li Y-J, et al. The miR-17-92 cluster expands multipotent hematopoietic progenitors whereas imbalanced expression of its individual oncogenic miRNAs promotes leukemia in mice. Blood. 2012;119:4486-4498. doi:10.1182/blood-2011-09378687

25. Pasqualini L, Bu H, Puhr M, et al. miR-22 and miR-29a are members of the androgen receptor cistrome modulating LAMC1 and Mcl-1 in prostate cancer. J Mol Endocrinol. 2015;29:1037-1054. doi:10.1210/ me.2014-1358

26. Huse JT, Brennan C, Hambardzumyan D, et al. The PTEN-regulating microRNA miR-26a is amplified in high-grade glioma and facilitates gliomagenesis in vivo. Genes Dev. 2009;23:1327-1337. doi:10.1101/ gad. 1777409

27. Meng F, Henson R, Wehbe-Janek H, Ghoshal K, Jacob ST, Patel T. MicroRNA-21 regulates expression of the PTEN tumor suppressor gene in human hepatocellular cancer. Gastroenterology. 2007;133:647-658. doi:10.1053/j.gastro.2007.05.022

28. Wu H, Zhang $\mathrm{W}, \mathrm{Wu} \mathrm{Z}$, et al. miR-29c-3p regulates DNMT3B and LATS1 methylation to inhibit tumor progression in hepatocellular carcinoma. Cell Death Dis. 2019;10:48. doi:10.1038/s41419-0181281-7

29. Valdmanis PN, Kim HK, Chu K, et al. miR-122 removal in the liver activates imprinted microRNAs and enables more effective microRNA-mediated gene repression. Nat Commun. 2018;9:5321. doi:10.1038/s41467-018-07786-7

30. Teufel M, Seidel H, Köchert K, et al. Biomarkers associated with response to regorafenib in patients with hepatocellular carcinoma. Gastroenterology. 2019;156:1731-1741. doi:10.1053/ j.gastro.2019.01.261

31. Liao ZB, Tan XL, Dong KS, et al. miRNA-448 inhibits cell growth by targeting BCL-2 in hepatocellular carcinoma. Dig Liver Dis. 2018. doi:10.1016/j.dld.2018.09.021

32. Bao J, Yu Y, Chen J, et al. MiR-126 negatively regulates PLK-4 to impact the development of hepatocellular carcinoma via ATR/ CHEK1 pathway. Cell Death Dis. 2018;9:1045. doi:10.1038/ s41419-018-1020-0

33. Shi D-M, Li L-X, Bian X-Y, et al. miR-296-5p suppresses EMT of hepatocellular carcinoma via attenuating NRG1/ERBB2/ERBB3 signaling. J Exp Clin Cancer Res. 2018;37:294. doi:10.1186/ s13046-018-0957-2

34. Liu Z, Li W, Pang Y, et al. SF3B4 is regulated by microRNA-133b and promotes cell proliferation and metastasis in hepatocellular carcinoma. EBioMedicine. 2018;38:57-68. doi:10.1016/j.ebiom. 2018.10.067 


\section{Publish your work in this journal}

OncoTargets and Therapy is an international, peer-reviewed, open access journal focusing on the pathological basis of all cancers, potential targets for therapy and treatment protocols employed to improve the management of cancer patients. The journal also focuses on the impact of management programs and new therapeutic agents and protocols on patient perspectives such as quality of life, adherence and satisfaction. The manuscript management system is completely online and includes a very quick and fair peer-review system, which is all easy to use. Visit http://www.dovepress.com/ testimonials.php to read real quotes from published authors. 